\title{
Olympic Education at Model Schools for the 2008 Beijing Olympic Games
}

\author{
Yimin Wang* and Naofumi Masumoto** \\ * Doctoral Program of the Graduate School of Human Health Science, \\ Tokyo Metropolitan University \\ 1-1 Minami Ohsawa, Hachioji, Tokyo 192-0397 Japan \\ **Department of Health Promotion Sciences, \\ Graduate School of Human Health Science, Tokyo Metropolitan University \\ 1-1 Minami Ohsawa, Hachioji, Tokyo 192-0397 Japan \\ [Received December 24, 2008; Accepted May 1, 2009; Published online December 10, 2009]
}

\begin{abstract}
The purpose of this research is first to determine the conditions of Olympic Education (OE) at model schools in the city of Beijing before the 2008 Beijing Olympic Games and second, to identify educational results and problems relating to $\mathrm{OE}$ in Beijing during different educational stages. The research methods included literature research, a questionnaire survey of students, and interviews with teachers. The results obtained are as follows: (1) A "reader book" was used as an $\mathrm{OE}$ material for physical education and other subjects at model schools; (2) Extracurricular activities at the model schools, such as traditional sports, mini Olympic Games, sporting events with local residents, and the installation of $\mathrm{OE}$ exhibits promoted understanding of Olympism; (3) OE at model schools was not conducted uniformly; and (4) OE programs were financially supported by trinity three-part structure system consisting of the government, municipal districts, and the model schools. The problems of the OE are summarized as follows: (1) Comprehension and satisfaction levels of junior and senior high school students were relatively low; (2) There is need for improvement in the methods of teaching about Olympism; (3) There should be more emphasis on Olympic knowledge as an important evaluation item; (4) The training system for teachers of other subjects is inadequate; and (5) The financial budgets of the government and the model schools were not disclosed, and this may make it difficult to develop OE programs at other schools in the future.
\end{abstract}

Keywords: Olympic Education, Beijing Olympic Games, model schools, extracurricular activities, evaluation

[International Journal of Sport and Health Science Vol.7, 31-41, 2009]

\section{Introduction}

In Olympic Education (OE), the International Olympic Committee (IOC) encourages the use of "Olympic themes to motivate students in mathematics, sciences, writing and reading, the arts and physical education" (IOC, 1995). According to Masumoto (2004), the purpose of $\mathrm{OE}$ is "to teach students fundamental knowledge and fundamental attitudes such as history, ideals and organization of the Olympic Games and also to learn about the ideals of the Olympism." This is an important part of the Olympic Movement based on the ideals of the Olympism under the direction of the IOC (IOC, 2009). Various OE programs were implemented in cities hosting the Olympic Games featuring their own ideas and characteristics based on the ideals of OE (JOA, 2008).

$\mathrm{OE}$ in China has been promoted primarily by the Chinese government since 2001, when the city of Beijing was selected to host the 2008 Olympic Games (Xin Hua Net, 2008). Since then, the Chinese government has implemented numerous plans such as the 2001-2010 National Health Plan Outline in 2001, the 2001-2010 Olympic Movement Promotional Plan in 2002, the Beijing 2008 Elementary and Secondary School Olympic Education Program in 2005, and the 11th 5-year Educational Plan (2006-2010) in 2006 (Wang and Masumoto, 2007). In accordance with these plans, the Beijing Organizing Committee for the Olympic Games (BOCOG) published Olympic readers starting in 2004 including the Junior and Senior High School Reader (HSR) (BOCOG, 2004) and the 
Elementary School Reader (ESR, BOCOG, 2005a, 2008a). The Chinese government tried to educate students on the three elements, namely the Olympic spirit, internationalism, and patriotism. Ren (2004) pointed out that "in order to obtain the best results, an original Olympic education program should be developed by combining the national traditional cultures of various countries and Olympism" and "at the same time carefully maintaining the tradition of the sports culture of the region and absorbing external sports culture simultaneously has been a major subject related to globalization."

On the other hand, there were some problems in the development of OE in China. For example, there was obviously a significant imbalance between urban and rural areas in terms of the educational opportunities because of economic differences, and there were also differences in terms of enthusiasm about $\mathrm{OE}$ among different cities. Based on a survey conducted on 1,200 junior high school students in 2005 in Beijing, Liu and Wang (2006) pointed out that at the time the Olympic knowledge of students was inadequate and there were insufficient number of qualified teachers and teaching materials for $\mathrm{OE}$ in China.

Based on the "Beijing 2008 Elementary and Secondary School Olympic Education Program," a model school system for OE was started in the city of Beijing in December 2005 (BOCOG, 2005b). The details of system were not available when 2008 Beijing Games concluded. No official report of the OE system has been published to examine what influence OE has had on students, what materials the students studied, or how well students understood the material. Although some short research reports concerning conditions at the model schools were issued (Wu, 2007; Zheng, 2007), these reports are not sufficient because they cover their own school activities only. Especially, there are no research about the model schools of $\mathrm{OE}$ in Beijing, based on the lived opinions of the stakeholders, that is, students and teachers of the OE. Because the model school system was developed mainly in the city of Beijing, it is important to survey the actual conditions of the model schools in Beijing from the stand point of students and teachers of model schools in order to expand OE throughout China.

The purpose of this research is first, to determine the status of $\mathrm{OE}$ at the model schools in Beijing before the 2008 Beijing Olympic Games, and second, to clarify the educational results and problems related to $\mathrm{OE}$ in Beijing at the respective educational stages.
As to the research method, because the researches about the model schools were little, first the materials from the BOCOG and the Beijing City OE website were referred mainly as documentation materials. Second, in order to analyze the lived opinion of the stake-holders, that is, students and teachers of the OE model schools, a questionnaire survey of students, and interviews with teachers were conducted.

This paper is divided into the following sections: (1) Model school policies and systems concerning OE in China; (2) The status of $\mathrm{OE}$ at model schools in Beijing; and (3) Based on these analytical results, an attempt to clarify the interim results and problems of $\mathrm{OE}$ at the model schools and identification of issues future $\mathrm{OE}$ in China.

\section{Model school policies and systems concerning $\mathrm{OE}$ in China}

\subsection{OE policies at model schools}

The Ministry of Education of China and BOCOG adopted the "Beijing 2008 Elementary and Secondary School Olympic Education Program" in 2005. Based on this Program, OE in China was started for the 400 million youth in China nationwide. Initially, $\mathrm{OE}$ was conducted in five venue cities: Beijing, Shanghai, Qingdao, Shenyang, and Qinhuangdao. The objectives of this OE were to disseminate the concepts of the Beijing Games, to teach information concerning the Olympic Games to youth, to promote enthusiasm for the Olympics, and to foster a spirit of fairness, justice, peace and friendship (China Education and Research Network, 2008).

In accordance with the Education Program, the Beijing Educational Steering Committee and the Beijing Board of Education developed an "OE action plan of for Beijing schools" and selected 200 model schools in Beijing for OE ahead of the rest of the country (Beijing Olympic Education, 2008a).

Selection of the model schools was based on conditions that the $\mathrm{OE}$ classes developed independently. Specifically, the class should meet for more than two hours every month and use HSR and ESR as basic teaching materials, and also athletic meeting are conducted incorporating the knowledge and concepts of the Olympic Games. From December 2005 to 2008, the 200 schools in Beijing and 356 schools in other parts of China were authorized as OE model schools. OE in China was developed mainly at 


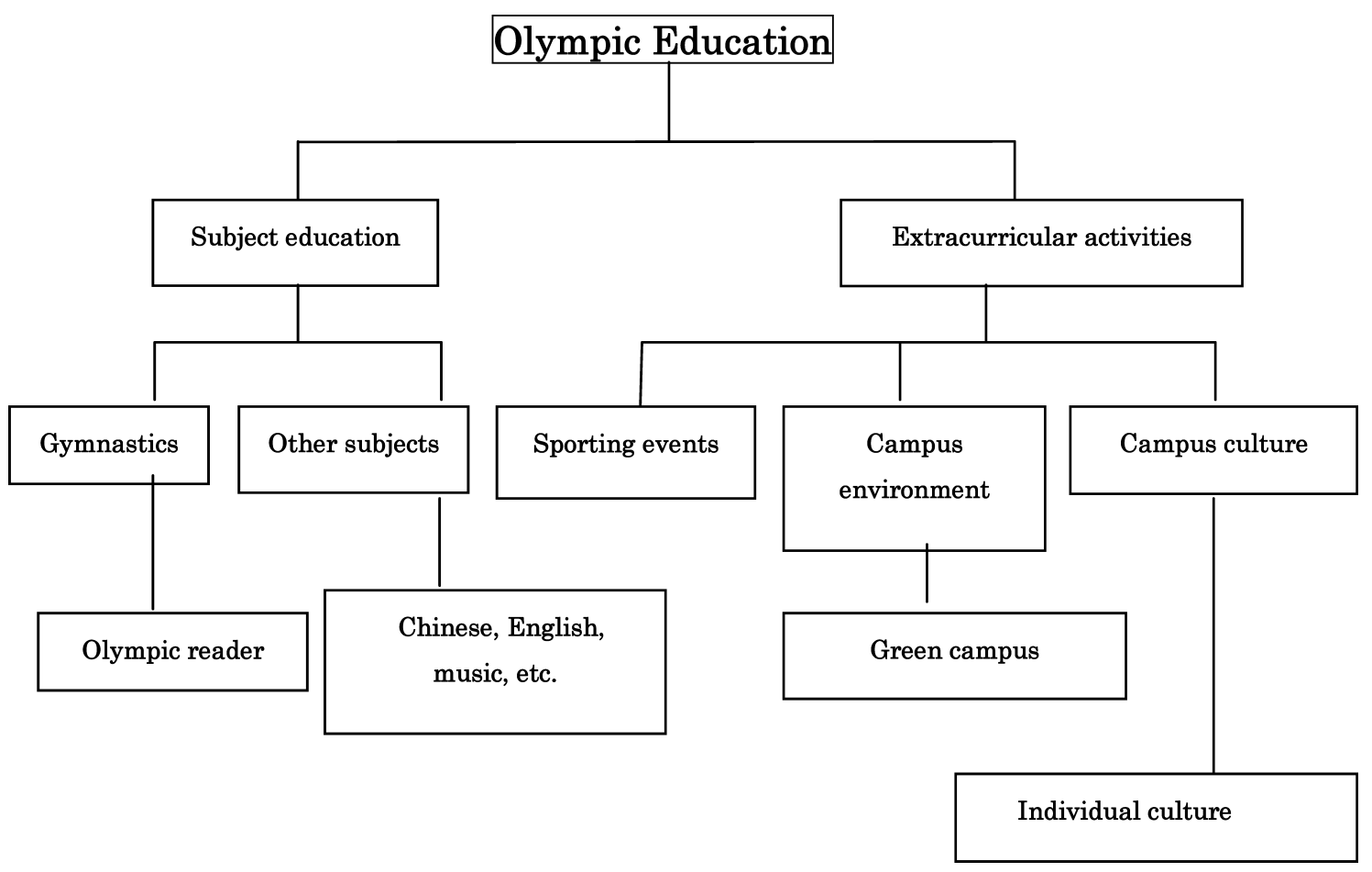

Figure 1 Structure of the Olympic educational programs

these schools. There were a total number of 556 model schools; 152 elementary schools and 404 junior and senior high schools (BOCOG, 2008b).

Once selected as a model school, each school was obliged to spend funds and actively train teachers. The amount of the funds differed depending on the particular circumstances of each school and the financial condition of the local government concerned (Chinese Teacher Resources Network, 2008). Funds for the model schools were provided by both the national government and cities. Recently, it seems that the educational funds of each school have been spent mainly on building gymnasiums so they can be selected as model schools. On the other hand, OE teacher training program was developed by local boards of education selecting a few teachers who were trained at teacher education universities. For example, the Beijing Educational Institute is one such training center in Beijing (Chinese Teacher Resources Network, 2008).

\subsection{System and program of $\mathrm{OE}$ at model schools}

The OE system and program are organized in accordance with the governmental OE plan and are developed mainly at model schools.

The model school system has a three-part structure consisting of the government, municipal districts and the model schools. The National OE Department adopts policies and the budget for OE every year. The local $\mathrm{OE}$ offices of the respective municipal districts supervise and guide the OE policies and plans for the model schools, and distribute educational funds. Usually one vice-principal and a few full-time teachers are assigned to OE at the model schools, and they are responsible for OE (Beijing Olympic Education, 2008a).

The OE program at the model schools consists of subject education and extracurricular activities (Beijing Olympic Education, 2008b). The subject education is divided into physical education and other subject education (Figure 1). Physical education is mainly conducted using the OE reader. In elementary schools, knowledge of the Olympic Games is taught using ESR story books that focus on the Olympic Games. In junior and senior high schools, knowledge of the Olympic Games is taught in more detail with the HSR (Beijing Olympic Education, 2008b).

In other subject education, knowledge of the Olympic Games is included as part of the curriculum and it is devised for students to understand the Olympic Games more easily. Although there are some differences among the various model schools, the content of $\mathrm{OE}$ is included in elementary school subjects, such as music, English, language, arts, 
science, and so on. For example, in the music course, the objective is to understand the festivity of the Olympic Games through singing the Olympic hymn. In the case of junior and senior high schools, the content of $\mathrm{OE}$ is included in Chinese, mathematics, chemistry, biology, geography, and so on. For example, in the Chinese course, the aim is to strengthen knowledge of the Olympic Games by students through expressing likes and dislikes about the Olympic Games and creating Olympic Games newspapers and other activities (Beijing Olympic Education, 2008c).

The extracurricular activities consist of three main parts; sporting events, campus environment, and campus culture. Annual sports meeting and miniOlympic Games conducted by class units are carried out as a part of sporting events. The elementary school program includes the pentathlon based on the ancient Olympic Games. For the campus environmental program, students are taught the importance of environmental protection through cleaning up their campuses or recycling used books, and so on. The campus culture education program seeking a balance between traditional Chinese sports culture and the Olympic Games was taken into account. Moreover, each school develops OE independently through information about the history of their schools and the Olympic Games, demonstrated in posters or $\mathrm{OE}$ exhibits (Beijing Olympic Education, 2008 d).

\section{Conditions of $\mathrm{OE}$ at the model schools}

\subsection{Survey of $\mathrm{OE}$ at the model schools}

Purpose: To clarify $\mathrm{OE}$ at the model schools in terms of both the form and content of learning and activities.

Survey period: June 11-28, 2007

Subjects: Students in elementary (about 900), junior and senior high schools (about 900) (in total about 1,800 of 10 schools), qualified teachers responsible for OE (five elementary school and five junior and senior high schools teachers, who were recommended as subjects by BOCOG, in total 10 schools teachers). ${ }^{1}$

Method: questionnaire survey and interview investigation; In order to determine the actual conditions, the questionnaire survey was carried out at 10 of the model schools in Beijing (distribution collection method).

According to the concept of "culture complex" (Sogawa,1991), the questionnaire and the interview were created according to the standpoint that $\mathrm{OE}$ is one culture and it exists and is developed in three dimensions, that is, the behavior culture, the mind culture, and the system culture. The mind culture was examined by the questionnaire to students, and the behavior culture and the system culture were studied by direct interviewing the teachers (half structured interview method).

The questionnaire consisted of five parts with 23 questions: (1) The ancient Olympic Games; (2) The modern Olympic Games; (3) The Beijing Olympic Games; (4) The Olympic Movement; and (5) Satisfaction with Olympic learning. These five parts of questionnaire were made up of the usual OE programs ((1), (2), (4)), special topics of the Beijing Games (3), and the satisfaction ratio (5). Three open questions were also presented, that is, (1) the contents of advanced learning of $\mathrm{OE}$, (2) expectations towards the BOCOG and IOC, and (3) how to utilize the OE in future. The scale of the answer to the questions was set to five. The median was set to 3: "neither yes nor no," and the responses "did not understand" were set at 1 and 2 and "understood" to 4 and 5 respectively (Table 1). Obtained results from the questionnaire survey were compared first by the mean of elementary school and junior and senior high school students, and second analyzed with multiple regression analysis (stepwise method) between the satisfaction with Olympic learning and other items.

On the other hand, interview investigation was carried out to the qualified teachers of model schools with half structured interview method. The questions of interview consisted of three parts: (1) Activity style of OE; (2) The contents of OE; and (3) Educational policies of the model schools of $\mathrm{OE}$ in Beijing. Responses from the teachers in these interviews were recorded into the hearing sheets and clarified with open coding of free answers. By the way, because this open coding method was carried out by the interviewer after backing to Japan from the survey in Beijing, this coding list was not checked by interviewees themselves.

Number of valid responses: (1) questionnaire survey; 694 (77\%) (356 boys, 338 girls) from

\footnotetext{
${ }^{1}$ As to the selection of the subjects of OE model schools in Beijing, because BOCOG selected and arranged the 10 schools as designated model schools, there were no loom for the subject selection for this survey.
} 
Table 1 Student evaluations of OE at model schools

\begin{tabular}{|c|c|c|c|c|c|c|c|c|c|c|c|}
\hline & \multicolumn{5}{|c|}{ Elementary schools $(\mathrm{n}=694)$} & \multicolumn{5}{|c|}{ Junior and high schools $(\mathrm{n}=759)$} & \multirow[b]{2}{*}{$p$} \\
\hline & $1,2(\%)$ & $3(\%)$ & $4,5(\%)$ & MEAN & $\mathrm{SD}$ & $1,2(\%)$ & $3(\%)$ & $4,5(\%)$ & MEAN & $\mathrm{SD}$ & \\
\hline \multicolumn{12}{|l|}{ (1) The ancient Olympic Games } \\
\hline Origin of the ancient Olympics & 7.8 & 13.8 & 77.2 & 4.10 & 1.02 & 13.8 & 15.5 & 70.5 & 3.79 & 1.14 & ** \\
\hline Meaning of the Olympic truce & 14.7 & 17.9 & 67.1 & 3.89 & 1.19 & 32.0 & 29.9 & 37.9 & 3.08 & 1.30 & $* *$ \\
\hline Events of the ancient Olympics & 4.2 & 6.5 & 88.8 & 4.39 & 0.86 & 12.0 & 21.3 & 66.5 & 3.66 & 0.96 & $* *$ \\
\hline Winners of the ancient Olympics & 7.9 & 11.4 & 80.3 & 4.31 & 1.05 & 18.4 & 28.5 & 53.1 & 3.51 & 1.13 & $* *$ \\
\hline \multicolumn{12}{|l|}{ (2) The modern Olympic Games } \\
\hline Pierre de Coubertin & 9.1 & 4.2 & 86.6 & 4.47 & 1.09 & 27.8 & 21.3 & 50.9 & 3.33 & 1.38 & ** \\
\hline The Coubertin creed & 19.7 & 20.0 & 59.4 & 3.66 & 1.32 & 33.6 & 24.2 & 42.0 & 3.13 & 1.37 & ** \\
\hline Meaning of the Olympic symbol & 3.2 & 6.8 & 89.6 & 4.51 & 0.79 & 8.0 & 11.5 & 80.5 & 4.25 & 1.02 & ** \\
\hline Torch relay & 5.8 & 3.2 & 85.2 & 4.36 & 0.96 & 9.0 & 17.3 & 73.8 & 3.97 & 1.01 & ** \\
\hline Meaning of the Olympic motto & 8.1 & 9.4 & 82.1 & 4.32 & 1.03 & 14.5 & 19.9 & 65.6 & 3.75 & 1.13 & ** \\
\hline Purpose of the Olympics & 4.6 & 8.9 & 86.2 & 4.42 & 0.91 & 7.6 & 12.5 & 79.8 & 4.10 & 1.00 & ** \\
\hline Paralympics & 5.5 & 7.1 & 87.3 & 4.45 & 0.93 & 10.5 & 18.3 & 71.1 & 3.85 & 1.02 & ** \\
\hline Prominent heroes in the Olympics & 6.1 & 8.9 & 84.9 & 4.36 & 0.97 & 10.4 & 18.7 & 70.9 & 3.81 & 1.04 & ** \\
\hline Olympics and the environment & 10.7 & 11.7 & 77.2 & 4.11 & 1.12 & 13.7 & 26.1 & 60.2 & 3.65 & 1.09 & ** \\
\hline \multicolumn{12}{|l|}{ (3) The Beijing Olympic Games } \\
\hline History of the Chinese Olympic movement & 9.7 & 14.1 & 76.1 & 4.10 & 1.10 & 14.1 & 24.4 & 61.5 & 3.60 & 1.09 & ** \\
\hline Slogan of the 29th Olympic Games & 6.2 & 6.8 & 87.0 & 4.53 & 0.96 & 9.9 & 10.7 & 79.4 & 4.18 & 1.11 & ** \\
\hline Three missions of the 29th Olympic Games & 6.6 & 10.1 & 83.3 & 4.39 & 1.01 & 12.0 & 18.8 & 69.2 & 3.95 & 1.17 & ** \\
\hline International exchange \& Heart-to-Heart & 9.2 & 10.7 & 79.4 & 4.24 & 1.10 & 16.2 & 26.2 & 57.6 & 3.59 & 1.16 & ** \\
\hline Volunteers of the Beijing Games & 6.8 & 10.4 & 82.6 & 4.33 & 1.00 & 8.2 & 12.1 & 79.7 & 4.11 & 1.03 & $* *$ \\
\hline \multicolumn{12}{|l|}{ (4) The Olympic Movement } \\
\hline Meaning of cultural programs & 16.7 & 13.3 & 56.8 & 4.18 & 1.07 & 9.2 & 20.0 & 70.6 & 3.88 & 1.05 & ** \\
\hline Significance of the peace movement & 5.0 & 7.1 & 87.8 & 4.45 & 0.90 & 8.2 & 16.2 & 75.6 & 4.04 & 1.04 & ** \\
\hline Fair play and anti-doping & 6.2 & 5.0 & 88.5 & 4.53 & 0.92 & 5.5 & 6.1 & 88.4 & 4.39 & 0.94 & ** \\
\hline Female participation, equality, non-discrimination & 5.3 & 6.8 & 87.5 & 4.45 & 0.92 & 7.1 & 11.5 & 81.3 & 4.21 & 1.03 & $* *$ \\
\hline (5) Satisfaction with Olympic learning & & & & & & & & & & & \\
\hline Satisfaction with $\mathrm{OE}$ & 3.6 & 4.8 & 90.6 & 4.59 & 0.80 & 12.0 & 19.2 & 68.5 & 3.81 & 1.08 & ** \\
\hline
\end{tabular}

elementary school students and 759 (84\%) (346 boys, 413 girls) from junior and senior high school students; and (2) interview investigation; 10 schools teachers.

Results: Table 1 is a comparison of the understanding levels of elementary school and junior and senior high school students.

This table shows that the comprehension of the elementary school is higher than the junior and senior high schools. Basically, OE in the model school should be taught for two hours every month using the readers. In the case of elementary school, since the study meetings concerning the Olympic Games were conducted for about 20 minutes every week (Table 3), it is estimated that the learning time in the elementary school is longer than junior and senior high schools. Lower comprehension levels were seen concerning the "Coubertin creed" (elementary school: 3.66, junior and senior high school: 3.13) and "the meaning of the Olympic Truce" (elementary school: 3.89, junior and senior high school: 3.08). It is thought that these two items were not addressed in the lessons because they are not described as important content in the readers.
On the other hand, because the interest level of nations to the Olympic Games has been rising in recent years and various examples are given and explained in the readers in detail, the comprehension levels for "fair play and anti-doping" (4.39), "the meaning of the Olympic symbol" (4.25), and "female participation, equality, and non-discrimination" (4.21), were relatively high in the junior and senior high schools.

The OE satisfaction levels in the elementary schools were very high (Table 1). Table 2 shows the result of multiple regression analysis of the factors concerning the satisfaction levels. The items that influence the satisfaction levels of both male and female students in the elementary school were "the Olympic Games and the environment," and the items that influence the satisfaction levels of both male and female students at junior and senior high schools were "the meaning of cultural programs," and "the slogan of the Beijing Games." However, it can be concluded that it is difficult to explain the satisfaction level of the students to the $\mathrm{OE}$ only from the comprehension level of the various learning items $\left(\mathrm{R}^{2}=0.196-0.348\right)$. 
Table 2 Factors influencing satisfaction levels (multiple regression analysis: stepwise method)

\begin{tabular}{|c|c|c|c|c|c|c|c|c|c|c|c|c|}
\hline & \multicolumn{6}{|c|}{ Elementary Schools $(n=694)$} & \multicolumn{6}{|c|}{ Junior and Senior High Schools $(\mathrm{n}=759)$} \\
\hline & \multicolumn{3}{|c|}{ Male students } & \multicolumn{3}{|c|}{ Female students } & \multicolumn{3}{|c|}{ Male students } & \multicolumn{3}{|c|}{ Female students } \\
\hline & \multicolumn{3}{|c|}{$\mathrm{n}=356$} & \multicolumn{3}{|c|}{$\mathrm{n}=338$} & \multicolumn{3}{|c|}{$\mathrm{n}=346$} & \multicolumn{3}{|c|}{$\mathrm{n}=413$} \\
\hline & Question & $\beta$ & Significance & Question & $\beta$ & Significance & Question & $\beta$ & Significance & Question & $\beta$ & Significance \\
\hline 1 & $\begin{array}{l}\text { The Olympics } \\
\text { and the } \\
\text { environment }\end{array}$ & 0.234 & $* * *$ & $\begin{array}{l}\text { Three missions } \\
\text { of the } 29 \text { th } \\
\text { Olympic Games }\end{array}$ & -0.186 & $* * *$ & $\begin{array}{l}\text { The meaning } \\
\text { of cultural } \\
\text { program }\end{array}$ & 0.184 & $* * *$ & $\begin{array}{l}\text { The meaning } \\
\text { of the Olympic } \\
\text { truce }\end{array}$ & 0.303 & $* * *$ \\
\hline 2 & $\begin{array}{l}\text { The origin of } \\
\text { the ancient } \\
\text { Olympics }\end{array}$ & 0.189 & $* * *$ & $\begin{array}{l}\text { The meaning } \\
\text { of the Olympic } \\
\text { motto }\end{array}$ & 0.164 & $* * *$ & $\begin{array}{l}\text { The slogan } \\
\text { of the 29th } \\
\text { Olympic Games }\end{array}$ & 0.159 & $* * *$ & $\begin{array}{l}\text { Fair play and } \\
\text { anti-doping }\end{array}$ & 0.150 & $* * *$ \\
\hline 3 & $\begin{array}{l}\text { Fair play and } \\
\text { anti-doping }\end{array}$ & 0.161 & $* * *$ & $\begin{array}{l}\text { The Olympics } \\
\text { and the } \\
\text { environment }\end{array}$ & 0.161 & $* * *$ & $\begin{array}{l}\text { History of the } \\
\text { Chinese Olympic } \\
\text { movement }\end{array}$ & 0.157 & $* * *$ & $\begin{array}{l}\text { The meaning } \\
\text { of cultural } \\
\text { programs }\end{array}$ & 0.142 & $* * *$ \\
\hline 4 & & & & $\begin{array}{l}\text { The slogan of } \\
\text { the 29th } \\
\text { Olympic Games }\end{array}$ & 0.156 & $* * *$ & $\begin{array}{l}\text { International } \\
\text { exchange \& } \\
\text { Heart-to-Heart }\end{array}$ & 0.152 & $* * *$ & $\begin{array}{l}\text { The slogan of } \\
\text { the 29th } \\
\text { Olympic Games }\end{array}$ & 0.131 & $* * *$ \\
\hline 5 & & & & $\begin{array}{l}\text { History of the } \\
\text { Chinese Olympic } \\
\text { movement }\end{array}$ & 0.130 & $* * *$ & $\begin{array}{l}\text { The meaning of } \\
\text { the Olympic } \\
\text { symbol }\end{array}$ & 0.134 & $* * *$ & & & \\
\hline 6 & & & & $\begin{array}{l}\text { Female } \\
\text { participation, } \\
\text { equality, no } \\
\text { discrimination }\end{array}$ & 0.127 & $* * *$ & & & & & & \\
\hline Adjusted $R^{2}$ & \multicolumn{3}{|c|}{$\mathrm{R}^{2}=0.196$} & \multicolumn{3}{|c|}{$\mathrm{R}^{2}=0.202$} & \multicolumn{3}{|c|}{$\mathrm{R}^{2}=0.348$} & \multicolumn{3}{|c|}{$\mathrm{R}^{2}=0.282$} \\
\hline
\end{tabular}

Taking the interview results into account, we can speculate that extracurricular activities about "the Olympic Games and the environment" are developed positively through research of the environment and the Olympic Games and waste collection and recycling of used paper in elementary schools (Table 3). On the other hand, we can also speculate that issues about "the meaning of the Olympic Games culture" and "the meaning of the Beijing Games" were taught and discussed by holding Olympic cultural festivals at the junior and senior high schools.

According to the answers to open questions, there were many who responded that they wanted to study the "ancient Olympics $(108)^{2}$," "the origin of the Olympic Games and rules (121)," "the mascots of the Games (33)," "stories of athletes (108)," and so on, as the advanced learning of $\mathrm{OE}$, at elementary, junior, and senior high schools. Expectations towards the BOCOG and IOC included "success of the Beijing Games (183)," "improvement of the environment of Beijing (70)," "volunteer participation (79)," "holding youth
Olympic Games (54)," and so on. There were opinions about how to disseminate information concerning the Olympic Games such that "effective activities in everyday life (551)," "more advertising (196)," and "implementing environmental protection (20)."

According to the half structured interviews with $\mathrm{OE}$ teachers, the form and the content of OE at elementary and junior and senior high school were classified into five categories with open coding: (1) class lessons; (2) workshops; (3) mini Olympic Games (athletic meeting, etc.); (4) activities in school (outside of classrooms); and (5) activities outside school (local events) (Table 3). The objectives of $\mathrm{OE}$ are increasing understanding of Olympism, cultivating international understanding, improving the manners of spectators, and disseminating knowledge of the Olympic Games through various means at elementary, junior, and senior high schools.

According to the half structured interviews about system culture, $\mathrm{OE}$ at the model schools was conducted based on the Beijing 2008 Elementary and Secondary School OE Program and the OE action plan for Beijing

2 ( ) shows the number of replies of same categories. 
Table 3 Activities and contents of $\mathrm{OE}$ at model schools (behavior culture) classified by the interviews

\begin{tabular}{|c|c|c|}
\hline Activity style & & Contents of OE \\
\hline \multirow[t]{2}{*}{ Lessons in the classroom } & Elementary schools & $\begin{array}{l}\text { Prepare a bulletin board about the Olympics } \\
\text { Hold Olympic study meetings (about } 20 \text { minute every week) } \\
\text { Study foreign languages with invited teachers from universities of foreign studies }\end{array}$ \\
\hline & Junior and high schools & $\begin{array}{l}\text { Develop an original Olympic textbook } \\
\text { Introduce the history of the Olympics and game rules, etc. } \\
\text { Study etiquette and manners }\end{array}$ \\
\hline \multirow[t]{2}{*}{ Workshops } & Elementary schools & $\begin{array}{l}\text { Make a presentation about the theme of the Olympics } \\
\text { Hold mini-Olympic lectures by class units }\end{array}$ \\
\hline & Junior and high schools & $\begin{array}{l}\text { Conduct debates and study meetings by class units (one term each) } \\
\text { Make a presentation about the Olympic spirit } \\
\text { Study race, culture, sport, etc. through the "one class, one country program" }\end{array}$ \\
\hline \multirow[t]{2}{*}{$\begin{array}{l}\text { Mini-Olympic } \\
\text { (Athletic meet etc.) }\end{array}$} & Elementary schools & $\begin{array}{l}\text { Hold a mini-Olympic athletic meet } \\
\text { Hold a sports meet } \\
\text { Hold a sports meet with community residents }\end{array}$ \\
\hline & Junior and high schools & $\begin{array}{l}\text { Hold a mini-Olympic athletic meet } \\
\text { Improve spectator manners through class matches } \\
\text { Hold a mini athletic meet involving students, teachers, and community residents }\end{array}$ \\
\hline \multirow[t]{2}{*}{$\begin{array}{l}\text { Activities at schools } \\
\text { (Outside of classroom) }\end{array}$} & Elementary schools & $\begin{array}{l}\text { Hold a drawing exhibition } \\
\text { Hold writing contest on the Olympic Games and myself } \\
\text { Hold speech contest on the "one class, one country program" } \\
\text { Hold poster exhibitions on the "one class, one country program" } \\
\text { Recycle used paper }\end{array}$ \\
\hline & Junior and high schools & $\begin{array}{l}\text { Hold Olympic cultural festivals } \\
\text { Hold poster exhibitions } \\
\text { Install Olympic advertisement exhibits } \\
\text { Install a Beijing Games countdown clock } \\
\text { Issue mini-Olympic newsletters } \\
\text { Make Olympic Games bulletin boards }\end{array}$ \\
\hline \multirow[t]{2}{*}{$\begin{array}{l}\text { Activity outside school } \\
\text { (Local events) }\end{array}$} & Elementary schools & $\begin{array}{l}\text { Talk about the Olympics with family members (during summer vacation) } \\
\text { Investigate the Olympic environment and garbage collection (during summer } \\
\text { vacation, at home and other areas) } \\
\text { Visit the BOCOG } \\
\text { Spread Olympic knowledge to local elementary schools }\end{array}$ \\
\hline & Junior and high schools & $\begin{array}{l}\text { Visit the Beijing Olympic venues } \\
\text { Visit the venue builders } \\
\text { Participate in environmental protection activities and local Olympic sport events } \\
\text { Conduct PR activities for the Beijing Games targeting community residents } \\
\text { Organize OE groups in the community } \\
\text { Plant trees and conduct "youth Olympic tree" activities }\end{array}$ \\
\hline
\end{tabular}

schools adopted by the government using a three-part structure including the Education Committee of each district. Furthermore, in order to carry out $\mathrm{OE}$ effectively, the qualified teachers and texts which were tailored to the conditions and characteristics of each model school were arranged other than the readers, and the fund was acquired based on the budget respectively. However, it seems that the OE training systems for other subject teachers were inadequate. 
Table 4 The evaluation sheet of OE at model schools in the Chaoyang district

\begin{tabular}{|c|c|c|c|c|c|c|}
\hline \multirow{2}{*}{ Item } & \multirow{2}{*}{ Content } & \multirow{2}{*}{ Weight } & \multicolumn{3}{|c|}{ Level \& scores } & \multirow{2}{*}{ Evaluation } \\
\hline & & & A & $\mathrm{B}$ & $\mathrm{C}$ & \\
\hline \multirow[t]{3}{*}{ School system } & Organization mechanism & 0.1 & 1 & 0.85 & 0.6 & \\
\hline & Cooperation and responsibility & 0.1 & 1 & 0.85 & 0.6 & \\
\hline & School system & 0.1 & 1 & 0.85 & 0.6 & \\
\hline \multirow{3}{*}{ Planning } & Planning & 0.1 & 1 & 0.85 & 0.6 & \\
\hline & Contents of the OE & 0.1 & 1 & 0.85 & 0.6 & \\
\hline & Execution of the planning & 0.1 & 1 & 0.85 & 0.6 & \\
\hline \multirow[t]{3}{*}{ Moral education } & $\mathrm{OE}$ and moral education & 0.3 & 3 & 2.55 & 1.8 & \\
\hline & OE and moral education activities & 0.5 & 5 & 4.25 & 3 & \\
\hline & OE and moral education evaluation & 0.3 & 3 & 2.55 & 1.8 & \\
\hline \multirow[t]{3}{*}{ Campus culture } & Exhibitions on the Olympic Games & 0.3 & 3 & 2.55 & 1.8 & \\
\hline & Dissemination activities of the Olympic knowledge & 0.3 & 3 & 2.55 & 1.8 & \\
\hline & Activities related to $\mathrm{OE}$ & 0.3 & 3 & 2.55 & 1.8 & \\
\hline \multirow[t]{3}{*}{ School education } & Development of OE subjects & 0.3 & 3 & 2.55 & 1.8 & \\
\hline & The situation of school hours and qualified teachers & 0.3 & 3 & 2.55 & 1.8 & \\
\hline & Learning effects & 0.2 & 2 & 1.7 & 1.2 & \\
\hline \multirow[t]{8}{*}{ Physical education } & Conditions of physical education in schools & 0.3 & 3 & 2.55 & 1.8 & \\
\hline & Establishment of subjects and reform of curricula & 0.3 & 3 & 2.55 & 1.8 & \\
\hline & Traditional Chinese physical education & 0.3 & 3 & 2.55 & 1.8 & \\
\hline & OE and physical education & 0.4 & 4 & 3.4 & 2.4 & \\
\hline & Campus sports culture & 0.3 & 3 & 2.55 & 1.8 & \\
\hline & One-hour of sporting activities per day & 0.5 & 5 & 4.25 & 3 & \\
\hline & Special features of school sporting activities & 0.4 & 4 & 3.4 & 2.4 & \\
\hline & Physical strength evaluation of students & 0.5 & 5 & 4.25 & 3 & \\
\hline International exchange & International exchange programs and the state of implementation & 0.2 & 2 & 1.7 & 1.2 & \\
\hline
\end{tabular}

\subsection{Features of $\mathrm{OE}$ programs and evaluation of the effects in the model schools}

From the results of the above survey, the features of OE model schools identified were as follows. (1) As shown in Table 3, it should be mentioned that $\mathrm{OE}$ is conducted by the entire school education system. OE includes not only the learning about the ancient Olympic Games, the modern Olympic Games, the Beijing Olympic Games, and the Olympic Movement, but also learning in other subjects. With this entireschool education system, understanding of the Olympic Games of students was deepened, and the learning satisfaction levels rose. (2) Extracurricular activities based on OE at the model schools are linked with local activities, and this promoted involvement by local residents in the Olympic Movement (Table 3). (3) According to the interview with model schools teachers, various $\mathrm{OE}$ programs other than uniform programs were conducted in accordance with actual conditions and features of the respective model schools (Table 3). (4) Qualified teachers were allocated to the model schools, and the educational effect was supervised an evaluated by the boards of education of each district (Table 4).

In order to monitor $\mathrm{OE}$ at the model elementary, junior and the senior high schools, the boards of education of each district inspected them every year and evaluated the effectiveness of $\mathrm{OE}$ based on evaluation sheets (Table 4). Although the standards of evaluation and the content vary, the purpose of the evaluations was to identify actual conditions and content $\mathrm{OE}$ and to improve $\mathrm{OE}$ in the model schools. For example, the board of education of the Chaoyang district evaluated the model schools using seven items, that is, "school system," "planning," "moral education," "campus culture," "class learning," "physical education" and "international exchange" (Table 4). 
According to this evaluation sheet, it seems that emphasis is put on "sporting activities," "physical strength evaluation," "physical education," "One-hour of sporting activities per day" and "moral education activity" in the Chaoyang district. The evaluation results were disclosed and used as a reference for evaluation standards at advanced OE schools and for applications for OE funds in the following fiscal year.

\section{Interim results and problems at the model schools}

\subsection{Interim results of the model schools}

The Beijing 2008 Elementary and Secondary School OE Program was established in 2005, and OE in China was started with the 400 million youth nationwide (Beijing Olympic Education, 2008e). The experiences of the model schools are important for developing OE in China. Based on these research results, the interim results of $\mathrm{OE}$ in the model schools can be summarized as follows.

First, in OE at the model schools, a reader is used in physical education and other subjects. The motivation of the students to learn about the Olympic Games was then raised using the entire school education system, and the student's level of understanding was also raised.

Second, the extracurricular activities of the model schools promoted participation levels in activities relating to the Olympic Games and deepened understanding of Olympism through traditional sports, mini Olympic Games, sports events with local residents, and installation of $\mathrm{OE}$ exhibits at model schools.

Third, OE at the model schools is not uniform, but is designed according to the features of each school, and the programs are unique according to their own campus cultures.

Fourth, OE is supported financially and systematically by a three-part structure consisting of government, municipal districts, and model schools. By training and assigning qualified teachers, such a system can be used to share the latest information and established OE lesson results. Moreover, the boards of education of each city and district supervise and evaluate the actual conditions of $\mathrm{OE}$ at the model schools, playing an effective role in promoting OE.

\subsection{Problem at the model schools}

While the results showed that the educational achievements of $\mathrm{OE}$ at the model schools were relatively high, they also brought to light various problems and issues.

First of all, the comprehension and satisfaction levels of Olympic learning in junior and senior high schools were lower than in elementary schools. It is necessary to investigate the reasons for this difference and to find more effective teaching methods and educational systems.

Second, it would appear that it is necessary to devise methods of learning about Olympism, such as the significance of the "Coubertin creed" and "cultural programs." Third, as shown in Chaoyang district, although sporting activities, physical education, and physical strength evaluation are listed as important items for OE evaluation, it is necessary to add Olympic knowledge as an important topic to learn.

Fourth, although information about the Olympics is taught in other subjects, it seems that the training system for teachers of other subjects is inadequate, and it cannot be determined whether these topics were taught to students effectively as shown in the evaluation sheet in Table 4.

Fifth, since neither governmental and local financial injections nor the budget of each model school is disclosed, it may be difficult to develop OE program at other schools in the future.

\section{Conclusion}

OE at the model schools was suitable for conditions in China and it has produced a new educational system. Because the educational structure consisting of government, municipal districts, and model schools supports $\mathrm{OE}$ with funding and the educational system, $\mathrm{OE}$ in China was adequately promoted. $\mathrm{OE}$ is not uniform, but various programs were conducted tailored to the actual conditions and the specific features of each model school, and moreover, it was developed through various theoretical and practical educations concerning the Olympic Games. On the other hand, since there were differences in learning levels, it may be necessary to develop $\mathrm{OE}$ programs according to learning levels.

Because of the limitations in these investigations, there are some important issues such as what kind of education was conducted in the "Heart-to-Heart 
Partnership Program"3 as part of OE at model schools and what kind of teaching was conducted in relation to the global torch relay of the Beijing Games, which created some turmoil. More difficult problems such as the relationships between the Olympic movement and politics as well as culture and religion, remain as future research issues.

\section{Acknowledgement}

This research was supported and arranged by Mr. Yang Zhi Cheng of the OE Division of BOCOG especially for the selection of the model schools.

\section{References}

Beijing Olympic Education (2008a), available online at: http:// www.bjedu.gov.cn/bjeduaoy/1227512373435170816/20060914/ 23016.shtml (in Chinese) (accessed 2nd February 2009)

Beijing Olympic Education (2008b), available online at: http:// www.bjoe.org.cn/bjeduaoy/1226958219574771712/20080421/ 37522.shtml (in Chinese) (accessed 7th February 2009)

Beijing Olympic Education (2008c), available online at: http:// www.bjoe.org.cn/bjeduaoy/1226958219574771712/20080424/ 37651.shtml (in Chinese) (accessed 7th February 2009)

Beijing Olympic Education (2008d), available online at: http:// www.bjoe.org.cn/bjeduaoy/1226952722016632832/20070115/ 27657.shtml (in Chinese) (accessed 7th February 2009)

Beijing Olympic Education (2008e), available online at: http:// www.bjoe.org.cn/bjeduaoy/1233141872969383936/20080519/ 38260.shtml (in Chinese) (accessed 5th March 2009)

BOCOG (2004). Junior and senior high school reader. Beijing publishing company (in Chinese)

BOCOG (2005a). Elementary school reader. China boy juvenile publishing company. (in Chinese)

BOCOG (2005b), available online at: http://www.beijing2008.cn/ 80/65/article211996580.shtml (in Chinese) (accessed 5th March 2009)

BOCOG (2006), available online at: http://en.beijing2008.cn/18/28/ article214002818.shtml, (in Chinese) (accessed 5th March 2009)

BOCOG (2008a), available online at: http://en.beijing2008.cn/ education/schools/ (in Chinese) (accessed 2nd February 2009)

BOCOG (2008b), available online at: http://www.beijing2008.cn/ 61/00/article212050061.shtml (in Chinese) (accessed 2nd February 2009)

China Education and Research Network (2008), available online at: http://www.edu.cn/ji_jiao_news_279/20080804/t20080804_ 313874.shtml (in Chinese) (accessed 2nd February 2009)

Chinese Teacher Resources Network (2008), available online at: http://www.jiaoshi.com.cn/main/news_5388.html (in Chinese) (accessed 2nd February 2009)

IOC (1995). IOC Commission for the International Olympic Academy and Olympic Education, by Deanna Binder, p.3.

IOC (2009), available online at: http://www.olympic.org/uk/passion/ studies/index_uk.asp (accessed 5th March 2009)

JOA (2008). The Comprehensive Guide to the Olympic Movement. Japan Olympic Academy, pp. 190-191. in Japanese
Liu, H. \& Wang, Z. (2006). Study of education concerning the Olympic Games in junior and senior high schools in Beijing. Metropolitan Sport Institute gazette, 11-18: pp. 53-55. (in Chinese)

Masumoto, N. (2004). Utilizing the Athens Olympic Games in physical education lessons. Taiiku-Ka Kyouiku, 52-1:30-33. (in Japanese)

Ren, H. (2004). Olympic Education in China. In JOA (ed.). The Olympic Movement in Asia. JOA, pp. 31-36.

Sogawa, T. (1991). Sports culture complex. Taiiku-no-Kagaku, 412:139-145. (in Japanese)

Wang, Y. \& Masumoto, N. (2007). The aims and objectives of Olympic Education in China: A theoretical and historical review. Philosophy of Sport and Physical Education. 29-2:109-123. (in Japanese)

Wu, S. (2007). Olympic understanding and promotion. In The Harmony of Civilizations and Prosperity for All: Reflections on the Civilization Modes of Humankind, pp. 100-103. Organizing Committee for Beijing Forum Courtyard No. 1, Peking University. (in Chinese)

Xin Hua Net (2008), available online at: http://news.xinhuanet. com/olympics/2008-08/04/content_8935083.htm (in Chinese) (accessed 5th March. 2009)

Zheng, H. (2007). The Harmony of Civilizations and Prosperity for All-Reflections on the Civilization Modes of Humankind. pp. 155-160. Organizing Committee for Beijing Forum Courtyard No. 1, Peking University. (in Chinese)

\footnotetext{
${ }^{3}$ With support of the International Olympic Committee, the program is endeavored to enhance exchange between students of the Beijingbased elementary and secondary schools and youngsters of the countries and regions where members of the Olympic Family come from, realize the wishes of "One World One Dream," and jointly pursue the Olympic ideal of "Unity, Friendship, Peace.” (BOCOG, 2006)
} 


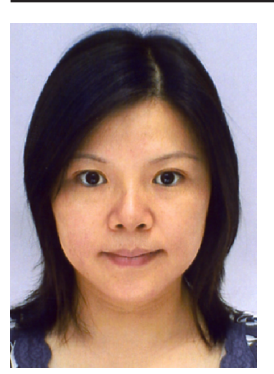

Name:

Yimin Wang

Affiliation:

Doctoral Program of the Department of Health Promotion Sciences, Graduate School of Human Health Science, Tokyo Metropolitan University

\section{Address:}

1-1 Minami Ohsawa, Hachioji, Tokyo 192-0397 Japan

\section{Brief Biographical History:}

2004- Master Program of the Graduate School of Education, Yokohama National University

2006- Doctoral Program of the Department of Health Promotion Sciences, Graduate School of Human Health Science, Tokyo Metropolitan University

\section{Main Works:}

- The aims and objectives of Olympic Education in China: A theoretical and historical review. Journal of the Philosophy of Sport and Physical Education. 29-2:109-123, 2007 (in Japanese)

- Defects in and reform of sports teams run by General Administration of Sports of China. Journal of Physical Education. 15-1:14-17, 2008 (in Chinese)

- Research on the harmonious development of the Chinese sports after the Beijing Olympic Games. Sports Culture Guide. 2:14-15, 2008 (in Chinese)

- Characteristic evaluation of Beijing Olympic Games "auspicious cloud" torch "travel of the harmony" relay. Journal of Physical Education. 15-11:21-24, 2008 (in Chinese)

Membership in Learned Societies:

- Japan Society of Physical Education, Health and Sport Sciences

- Japan Society for the Philosophy of Sport and Physical Education

- Japan Olympic Academy

- China Sport Science Society 